\title{
Surgical Management for Intractable Epilepsy in Medial Temporal Lobe Lesions (Al-Azhar Experience)
}

\section{Alaa Rashad Ibrahim ${ }^{1, *}$ MD, Mohamed Hamed Rashad ${ }^{2}$ MD.}

\author{
* Corresponding Author: \\ Alaa Rashad Ibrahim \\ alaarashad81@yahoo.com
}

Received for publication November 30, 2021; Accepted January 21, 2022; Published online January 21, 2022.

Copyright The Author published by Al-Azhar University, Faculty of Medicine, Cairo, Egypt. Users have the right to read, download, copy, distribute, print, search, or link to the full texts of articles under the following conditions: Creative Commons Attribution-Share Alike 4.0 International Public License (CC $B Y-S A$ 4.0)

doi: 10.21608 /aimj.2022.108309.1690

${ }^{I}$ Neurosurgery Department, Faculty of medicine, Al-Azhar university, Cairo, Egypt

${ }^{2}$ Neurology Department, Faculty of medicine, Al-Azhar university,

Cairo, Egypt

\section{ABSTRACT}

Background: The most common cause of drug resistant epilepsy is the temporal lobe seizures especially that caused by medial temporal lobe epileptogenic lesions.

Aim of the work: To assess the clinical outcome of medial temporal lobe lesionectomy (without amygdalo-hippocampectomy) in control of seizures in a group of drug resistant epileptic patients.

Patients and Methods: This study was conducted on 12 patients $(8$ males) presented to Al-Azhar university hospitals between October, 2018 and December, 2020 with drug resistant -temporal lobe- epilepsy due to medial temporal lobe lesions of different pathological natures not affecting the hippocampus, the lesions were surgically excised and had been followed up in out-patient clinic.

Result: This study revealed that all patients presented with drug resistant epilepsy with medial temporal lobe lesions, underwent surgical excision of the lesions without amygdalo-hippocampectomy and followed up for at least 10 months. The post-operative outcome of epilepsy was evaluated by Engel classification system with all patients becoming grade I (6 patients 50\% already stopped anti-epileptics -AEDs- , while the remaining $50 \%$ of patients is still on AEDs but with significant reduction of doses and number of AEDs). No memory affection or complications of significant long term sequel were observed. Conclusion: Medial temporal lobe lesionectomy without amygdalohippocampectomy carries significant clinical improvement of seizures in drug resistant epilepsy caused by medial temporal lobe lesions.

Keywords: Epilepsy surgery; drug resistant epilepsy; medial temporal lobe; lesions; amygdalo-hippocampectomy.

Disclosure: The authors have no financial interest to declare in relation to the content of this article. The Article Processing Charge was paid for by the authors.

Authorship: All authors have a substantial contribution to the article.

\section{INTRODUCTION}

Medial temporal lobe lesions mean lesions other than medial temporal sclerosis. Medial temporal lesions are the most common brain lesions causing drug resistant epilepsy. Usually treating the drug resistant epilepsy due to these lesions is excision of these lesions associated with amygdalo-hippocampectomy. In this paper we will assess the effect of excision of the lesions only without amygdalo-hippocampectomy on controlling the drug resistant epilepsy and the clinical outcome.

Medial temporal lobe is the part of temporal lobe that lies medial to the collateral sulcus and inferior to the temporal horn. Medial temporal lobe contains the following structures: parahippocampal gyrus, hippocampus, the uncus and the amygdale. ${ }^{1}$

The medial side of the temporal lobe is the most complicated surface of cerebral surfaces. For a better understanding, Fernández-Miranda et al. divided this surface into three segments: anterior, middle, and posterior segment. ${ }^{2}$
The anterior part of the medial temporal lobe is formed mostly by the uncus and the entorhinal cortex. The uncus has anterior and posterior segments, which come together at a medially directed prominence, the apex of the uncus. ${ }^{3}$

The middle part of the medial temporal lobe, when viewed medially, is formed from inferior to superior by the parahippocampal gyrus, the dentate gyrus, and the fimbria of fornix.

The posterior part of the medial temporal lobe is formed by the posterior end of the parahippocampal gyrus, which is divided by the anterior end of the calcarine sulcus into the isthmus of the cingulate gyrus superiorly and the lingual gyrus inferiorly, the quadrigeminal cistern is located medial to the posterior part of medial temporal lobe. ${ }^{3}$

The medial temporal lobe plays a central role in memory processing and is more than just the hippocampus. The hippocampal formation, which forms the upper segment of the medial temporal lobe, is a heterogeneous structure consisting of the 
Ammon horn or Cornus Ammonis (Cornus Ammonis area 1 to Cornus Ammonis area 4) and the dentate gyrus appearing as 2 interlocking U's on a coronal image. $^{4}$

Medial temporal lobe lesions other than medial temporal sclerosis that cause seizures are usually composed of focal cortical dysplasia (FCD), vascular lesions as cavernomas or may be tumors. Medial temporal tumors may be mixed neuronal and glial tumors (MNGTs), such as dysembryoplastic neuroepithelial tumors (DNT) and ganglioglioma meaning low grade lesions or higher grade lesions as astrocytomas. $^{5}$

Up to $25 \%$ of temporal lobe epilepsy may be related to temporal lobe tumors and usually the age of onset of seizures during childhood and adolescence. ${ }^{6}$

Management of medial temporal lobe lesions causing intractable epilepsy is to totally excise the lesions with or without amygdalo-hippocampectomy or with only hippocampal trans-section to disrupt the epileptogenic circuit without affecting the memory circuit. $^{7}$

There are different systems used to evaluate of the outcome of epilepsy surgeries. One of the most popular scales is Engel classification system. The Engel classification system: Class I-No disabling seizures. Class II-Rare disabling seizures. Class III-Worthwhile improvement. Class IV-No worthwhile improvement. ${ }^{8}$

This study was done to describe Al-Azhar University Hospitals experience in doing surgical excision of medial temporal lobe lesions without amygdalohippocampectomy for cases with drug-resistant temporal lobe epilepsy, to show their clinical outcome and the results and drawbacks of excision of only the medial temporal lesions without amygdalohippocampectomy on controlling the drug resistant epilepsy.

\section{PATIENTS AND METHODS}

This study is consecutive series of 12 patients (8 males) presented between October, 2018 and December, 2020 to Al-Azhar University Hospitals (Al-Hussien and Sayed Galal University Hospitals) with drug resistant -temporal lobe- epilepsy with generalization in only four patients due to medial temporal lobe lesions with age ranged from 6months-old to age 39-year-old. These patients were managed with surgical excision of the lesions in the medial temporal lobe without amygdalohippocampectomy.

\section{Data collection and processing}

All patients' data were gathered and saved in summary sheets. Hospital records and radiology images of the patients were electronically saved and analyzed to meet our specific needs. The studying of the epilepsy semiology and its epileptogenesis focus and also neuropsychological assessments were recorded as per the neurologist and the neurosurgeon's preoperative assessment. The preoperative investigations and assessment were electronically collected and saved. The decision of surgery was taken after agreement of the all members of epilepsy team. The statistics were made from the master table (Table 1) containing relevant history, clinical and radiological data taken from the summary sheets and images. All percentages were approximated to two decimal places. This study was approved by the Scientific Committee in neurosurgery department, faculty of medicine for boys in Cairo, Al-Azhar University.

\section{Pre-operative evaluation}

All patients were evaluated clinically by our epilepsy team (consists of neurologist and neurosurgeon), radiological by Brain CT and MRI with and without contrast and also by repeated scalp EEGs in association with mobiles videos to evaluate the semiology of seizures. And after detailed discussion in the epilepsy meeting and confirming that the medial temporal lesion is the cause of patients' drugresistant epilepsy, the decision of surgery was taken.

Informed consent was taken for all patients in this study after explanation the procedure in simple words with also explanation to the possible complications that may happen and also clarifying the expected success in controlling the epilepsy and the post-operative course and follow-up.

\section{The surgical procedure}

After discussion with the whole epilepsy team and tailoring the best surgical approach and intervention for each patient, the informed consent from all patients was taken.

In eleven cases we approached through pterional approach with only linear incision in skin and temporalis muscle then free bone flap elevation as in figure1.
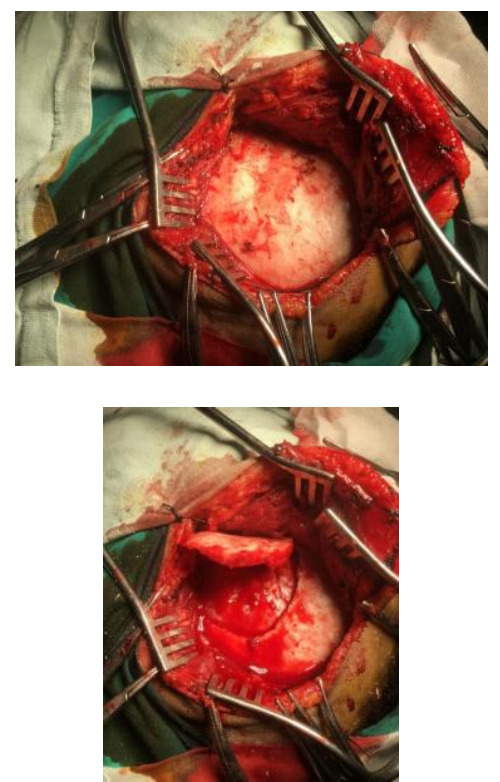

Fig. 1: Intra-operative photos of a case in our study to show the way of our pterional approach to medial temporal lobe lesions. 


\begin{tabular}{|c|c|c|c|c|c|c|c|c|c|}
\hline \multirow[t]{2}{*}{ Case no. } & \multicolumn{4}{|c|}{ clinical picture } & \multirow{2}{*}{$\begin{array}{l}\text { Lesion } \\
\text { type }\end{array}$} & \multirow{2}{*}{$\begin{array}{l}\text { Surgical } \\
\text { approach }\end{array}$} & \multirow[t]{2}{*}{ Complications } & \multirow[t]{2}{*}{ Engles grade } & \multirow{2}{*}{$\begin{array}{l}\text { Follow-up } \\
\text { duration }\end{array}$} \\
\hline & $\operatorname{sex}$ & $\begin{array}{c}\text { Age } \\
\text { (years) }\end{array}$ & presentation & $\begin{array}{c}\text { Duration of } \\
\text { epilepsy }\end{array}$ & & & & & \\
\hline 1 & Male & 36 & $\begin{array}{l}\text { Complex partial } \\
\text { seizures }\end{array}$ & $10 \mathrm{yrs}$ & $\begin{array}{l}\text { Left uncal } \\
\text { cavernoma }\end{array}$ & Trans-sylvian & non & Grade I & $2 \mathrm{yrs}$ \\
\hline 2 & Female & 35 & $\begin{array}{l}\text { Complex partial } \\
\text { seizures }\end{array}$ & $15 \mathrm{yrs}$ & $\begin{array}{c}\text { Left } \\
\text { ganglioglio } \\
\text { ma }\end{array}$ & Trans-cortical & $\begin{array}{c}\text { Behavior } \\
\text { changes for } 2 \\
\text { months }\end{array}$ & Grade I & $2 \mathrm{yrs}$ \\
\hline$\overline{3}$ & Male & $\begin{array}{c}0.5 \\
(6 \\
\text { months })\end{array}$ & Serial focal fits & $\begin{array}{l}\text { For one } \\
\text { month }\end{array}$ & $\begin{array}{c}\text { Rt. } \\
\text { Arachnoid } \\
\text { cyst }\end{array}$ & $\begin{array}{l}\text { Endoscopic } \\
\text { fenestration }\end{array}$ & $\begin{array}{l}\text { Needed re-do } \\
\text { only for } \\
\text { second time }\end{array}$ & Grade I & $2 \mathrm{yrs}$ \\
\hline$\overline{4}$ & Male & 26 & $\begin{array}{c}\text { Atypical } \\
\text { Absence attacks } \\
\text { and generalized } \\
\text { tonic seizures }\end{array}$ & $6 \mathrm{yrs}$ & $\begin{array}{c}\text { Lt. } \\
\text { pleomorphic } \\
\text { xanthoastroc } \\
\text { ytoma } \\
\text { (WHO GII) }\end{array}$ & Sub-temporal & $\begin{array}{c}\text { Non and on } \\
\text { with AEDs } \\
\text { withdrawal } \\
\text { the seizure } \\
\text { recur so more } \\
\text { slow } \\
\text { withdrawal } \\
\text { done }\end{array}$ & $\begin{array}{l}\text { Grade I but still } \\
\text { on small dose of } \\
\text { An-epileptics. }\end{array}$ & $2 \mathrm{yrs}$ \\
\hline 5 & Female & 13 & $\begin{array}{l}\text { Atypical } \\
\text { Absence attacks } \\
\text { and generalized } \\
\text { tonic seizures }\end{array}$ & $6 \mathrm{yrs}$ & $\begin{array}{c}\text { Lt. } \\
\text { ganglioglio } \\
\text { ma }\end{array}$ & Trans-sylvian & non & Grade I & $2 \mathrm{yrs}$ \\
\hline 6 & Female & 6 & $\begin{array}{c}\text { Atypical } \\
\text { Absence attacks } \\
\text { and generalized } \\
\text { tonic seizures }\end{array}$ & 3 yrs & $\begin{array}{c}\text { Lt. } \\
\text { ganglioglio } \\
\text { ma }\end{array}$ & Trans-sylvian & $\begin{array}{l}\text {-Contra- } \\
\text { lateral hemi- } \\
\text { pariesis } \\
\text { which } \\
\text { completely } \\
\text { resolved in } \\
\text { only one } \\
\text { month } \\
\text {-Residual of } \\
\text { prepontine } \\
\text { part of the } \\
\text { lesion }\end{array}$ & Grade I & 2 years \\
\hline 7 & Male & 12 & $\begin{array}{c}\text { Atypical } \\
\text { Absence attacks } \\
\text { and generalized } \\
\text { tonic seizures }\end{array}$ & $7 \mathrm{yrs}$ & $\begin{array}{c}\text { Rt. } \\
\text { Oligodendro } \\
\text { glioma GII }\end{array}$ & Trans-sylvian & $\begin{array}{l}\text { Residual part } \\
\text { of the lesion }\end{array}$ & Grade I & 2 years \\
\hline 8 & Male & 20 & $\begin{array}{c}\text { Atypical } \\
\text { Absence attacks }\end{array}$ & $5 \mathrm{yrs}$ & $\begin{array}{c}\text { Rt. } \\
\text { pleomorphic } \\
\text { xanthoastroc } \\
\text { ytoma } \\
\text { (WHO GII) }\end{array}$ & Sub-temporal & non & $\begin{array}{l}\text { Grade I but still } \\
\text { on medical ttt. }\end{array}$ & 15 months \\
\hline 9 & Female & 39 & $\begin{array}{c}\text { Atypical } \\
\text { Absence attacks }\end{array}$ & $2 \mathrm{yrs}$ & $\begin{array}{c}\text { Lt. } \\
\text { Arachnoid } \\
\text { cyst }\end{array}$ & Trans-sylvian & non & $\begin{array}{l}\text { Grade I but still } \\
\text { on medical ttt. }\end{array}$ & 15 months \\
\hline 10 & Male & 18 & $\begin{array}{c}\text { Atypical } \\
\text { Absence attacks }\end{array}$ & 4 yrs & $\begin{array}{c}\text { Rt. Pilocytic } \\
\text { astrocytoma } \\
\text { (WHO grade } \\
\text { I) }\end{array}$ & Sub-temporal & non & $\begin{array}{l}\text { Controlled but } \\
\text { still on medical } \\
\text { ttt. }\end{array}$ & 10 months \\
\hline 11 & Male & 16 & $\begin{array}{c}\text { Atypical } \\
\text { Absence attacks }\end{array}$ & 5 months & $\begin{array}{l}\text { Rt. } \\
\text { Glioblastom } \\
\text { a multiform } \\
(\mathrm{GBM})\end{array}$ & Trans-sylvian & non & $\begin{array}{l}\text { Grade I but still } \\
\text { on medical ttt. }\end{array}$ & 10 months \\
\hline 12 & Male & 6 & $\begin{array}{l}\text { Complex partial } \\
\text { seizures }\end{array}$ & 2 years & $\begin{array}{c}\text { Rt. } \\
\text { ganglioglio } \\
\text { ma grade I }\end{array}$ & Trans-sylvian & non & $\begin{array}{l}\text { Grade I but still } \\
\text { on medical ttt. }\end{array}$ & 10 months \\
\hline
\end{tabular}

Table1: is the master table showing clinical pictures, surgical data and post-operative complications and outcome. 
The approach to the medial temporal region was done either trans-sylvian, trans-cortical through the middle temporal gyrus; or sub-temporal. The approach chosen was depending on the site of lesion and surgeon preference figure 2 .

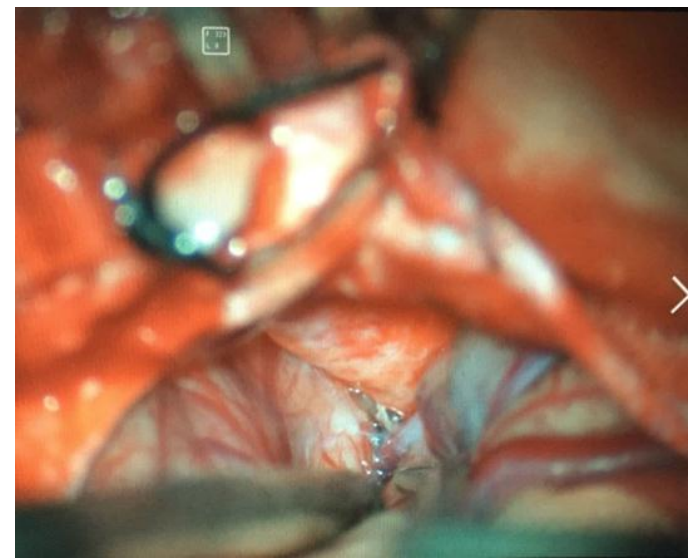

Fig. 2: Intra-operative photo of a case in our study to show the trans-sylvian approach to a right medial temporal lobe lesion.

In one case we approached the arachnoid cyst causing the epilepsy seizures by endoscopy for fenestration on the basal cistern which needed redo after only 2 weeks.

First case (case number 4)

\section{Illustrative cases}

Male patient 26 year old presented with 6 years history of generalized tonic seizures preceded with aura (automatism, excessive salivation and staring look) and also with history of recurrent attacks of absence. The frequency of the seizures gradually increased and became resistant to medical treatment although adequate drugs and the therapeutic doses.

Although the patient was on two types of antiepileptic drugs with maximum adequate doses he had 2 or 3 attacks per week which affect his life.

The patient was on sodium valproate $1500 \mathrm{mg}$ in the morning and $1000 \mathrm{mg}$ at night and also on carbamazepine CR 400mg twice per day.

Pre-operative brain imaging (figure 3 ) revealed left medial temporal lobe lesion and on the electroencephalography (EEG), there was abnormal waves were located at the left anterior temporal area.

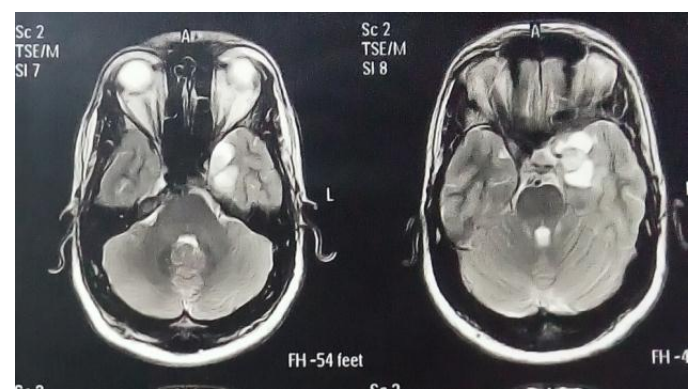

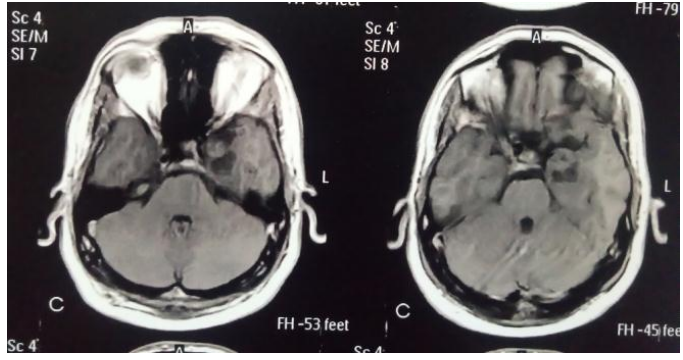

Fig. 3: Brain MRI T2 (on left) and T1 (on right) which revealed left medial temporal lesion affecting uncus and other parts of medial temporal lobe.

The patient was operated on using sub-temporal approach with complete lesion excision without intra-operative or post-operative complications and good direct post-operative CT Brain (figure 4).

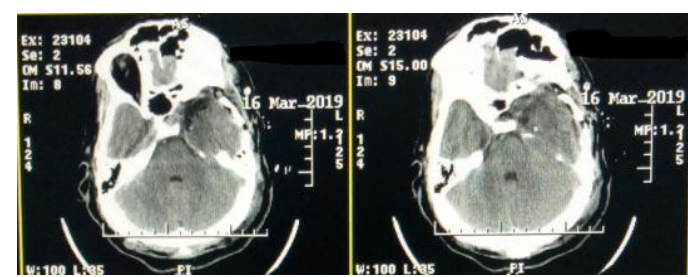

Fig. 4: Early post-operative CT Brain revealed no hemorrhage or other complications.

The patient discharged from the hospital on 3rd day with no seizures on early post-operative days. The pathology of the lesion was pleomorphic xanthoastrocytoma (WHO GII) and good follow up (after 8 months) Brain MRI as shown in figure 5.

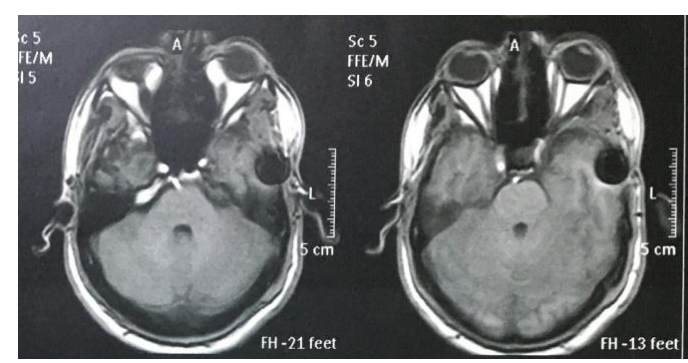

Fig. 5: Post-operative MRI Brain T1 revealing good mass excision with only metallic artifact.

The patient followed for 6 months with no even one seizure and after 6 months we started anti-epileptics withdrawal and now after 2 years he is on only one drug (carbamazepine CR 200mg once daily) with epilepsy good control Engel classification GI .

Second case (case number 6)

Female patient 6 year old presented with $r$ years history of generalized tonic-clonic seizures preceded with aura (in form of staring look) and also with history of recurrent attacks of absence. The frequency of the seizures gradually increased and became resistant to medical treatment although adequate anti-epileptic drugs and the therapeutic doses.

Although the patient was on three types of antiepileptic drugs with maximum adequate doses she had 4 or 5 attacks per week which affected her life. 
The patient was on Topiramate tablets $50 \mathrm{mg}$ twice daily, levetiracetam syrup $600 \mathrm{mg}$ twice per day and also on carbamazepine $2 \%$ syrup $160 \mathrm{mg}$ three times per day.

Pre-operative brain imaging (figure f) revealed left temporal lobe lesion with involvement of the choroid fissure, left side of pre-pontine cistern and extending to left cerebello-pontine angle; and on the electroencephalography (EEG), there was abnormal waves were located at the left temporal area.

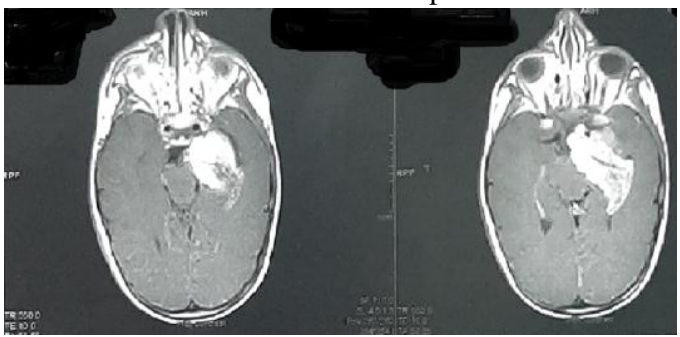

Fig. 6: Brain MRI T1 with contrast which revealed left medial temporal lesion with involvement of the choroid fissure, left side of pre-pontine cistern.

The patient was operated on using trans-sylvian approach with incomplete lesion excision but the medial temporal lesions was excised leaving parts in posterior fossa without intra-operative or postoperative complications and good post-operative MRI Brain (figure 7).

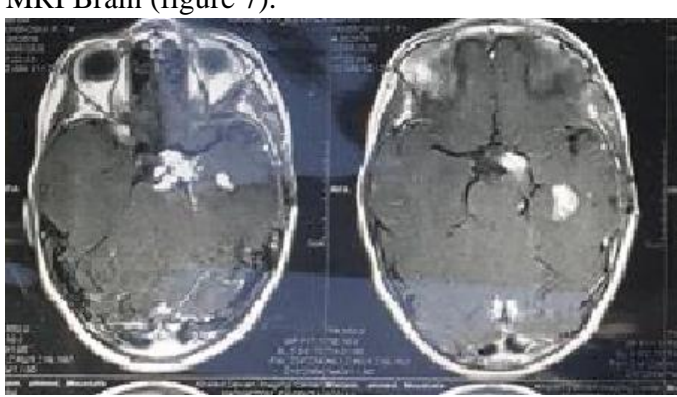

Fig. 7: After 1 year Post-operative MRI Brain T1 with contrast revealing incomplete lesion excision but the medial temporal lesions was excised leaving parts in posterior fossa.

The patient discharged from the hospital on 5th day with no seizures on early post-operative days and with intact neurological examination. The pathology report revealed that the diagnosis is Lt temporal ganglioglioma (WHO grade I).

The patient followed for 6 months with no even one seizure or aura and after 6 months we started antiepileptics withdrawal and now after 2 years she had no even aura and she is on only (carbamazepine $2 \%$ syrup 60mg twice daily and levetiracetam syrup $600 \mathrm{mg}$ twice per day) with epilepsy good control Engel classification GI and improved general and mental condition.

\section{RESULTS}

In this study we followed up 12 patients ( 8 males- 4 females) presented with drug resistant -temporal lobe- epilepsy with generalization in four patients and all were managed with surgical excision.
The cases underwent surgical excision were 8 males and 4 females with age distribution from 6 months to 39 years old with mean age 18.96 .

All cases presented with temporal lobe epilepsy which proceeded with aura and only four cases suffered from progression to generalized tonic-clonic seizures and they all were drug-resistant and so they sought surgical intervention for controlling the condition.

The all twelve cases had medial temporal lobe lesions 6 cases on left side and 6 cases had lesions on right side and all cases had intact hippocampus without infiltration or affection even in form of change in its intensities in Brain MRIs.

The approach to the lesions was tailored regarding the conditions of each case and so we approached in 7 cases trans-sylvian, in 3 cases sub-temporal, in one case trans-cortical and in one case through endoscopic fenestration of the right medial temporal arachnoid cyst causing serial fits not controlled medically which needed another redo endoscopic fenestration for second time after 2 weeks.

There were different pathologies of the medial temporal lobe lesions in our study, there were one cavernoma, two arachnoid cyst, two pleomorphic xantho-astrocytoma WHO G II, one pilocytic astrocytoma WHO G I, one oligodendroglioma G II, four Ganglioglioma and one case glioblastoma multiform (GBM).

\begin{tabular}{|l|c|}
\hline \multicolumn{1}{|c|}{ The lesion } & Patient numbers (\%) \\
\hline Ganglioglioma & Four patients (33.33\%). \\
\hline $\begin{array}{l}\text { Pleomorphic } \\
\text { astrocytoma WHO GII }\end{array}$ & Two patients (16.67\%). \\
\hline Arachnoid cyst & Two patients (16.67\%). \\
\hline Cavernoma & One patient (8.33\%). \\
\hline $\begin{array}{l}\text { Pilocytic astrocytoma (WHO } \\
\text { grade I) }\end{array}$ & One patient (8.33\%). \\
\hline Oligodendroglioma G II & One patient (8.33\%). \\
\hline Glioblastoma Multiform (GBM) & One patient (8.33\%). \\
\hline
\end{tabular}

Table 2: shows percentages of pathological nature of each medial temporal lobe lesions in the study.

Seven patients of the twelve cases followed-up for 2 years, 2 cases followed-up for 15 months and the other 3 cases followed-up for only 10 months at time of editing this paper and no case of them had any early seizure (during first months post-operatively) even minor aura with great satisfaction.

Then we started to withdrawal Anti-Epileptic Drugs (AEDs) gradually to all cases 6 months postoperatively with no recurrence of seizers during the withdrawal in 6 cases until we stopped the all AEDs and following them with Engle grade 1 epilepsy control. But in one case on withdrawal the last antiepileptic drug dose he used, he just complained of absence so we reused the previous dose he was taking and then he became completely controlled on small dose of single anti-epileptic drug.

The 5 cases we are following for 10 and 15 months only, none of them had any seizure and their AEDs are still withdrawn gradually with very good control of epilepsy with Engel grade I. 
Only 2 cases had post-operative complications which were temporary. One case had contra-lateral hemipariesis which completely resolved in only one month and this case was left sided with large lesion entering the choroid fissure and with extension to posterior fossa and although good epilepsy control the case needs another sitting for complete excision.

The other case with complication had sensory dysphasia and behavior changes which also improved gradually in 2 months and this case was approached trans-gyral and it was on left side.

There was a case with post-operative $\mathrm{CT}$ brain revealing hypodense area (radiological complication) without any neurological clinical abnormalities.

\section{DISCUSSION}

The medial side of the temporal lobe is the most complicated surface of cerebral surfaces. ${ }^{2}$

This area is close to the hippocampus and amygdala and so any lesion nearby can cause temporal lobe epilepsy which can be drug-resistant and so need surgical excision of the lesion and some surgeon add to tumor excision amygdalo-hippocampectomy to get the best epilepsy control. ${ }^{7}$

If there is any availability to avoid affecting the amygdala or hippocampus during the surgery on medial temporal lobe, you will have the best results without affection of the patient's memory and so some do only hippocampal trans-section to disrupt the epileptogenic circuit without affecting the memory circuit. ${ }^{7}$

The most common lesions in the medial temporal lobe are gangliogliomas then the astrocytomas followed by other low grade lesions like oligodendrogliomas and pleomorphic xanthoastrocytoma. $^{9}$

Drug-resistant epilepsy is more common in lowgrade tumors than in higher grade lesions that occurs in the medial temporal lobe. ${ }^{5}$

The most common lesions in this study were gangliogliomas $(33.33 \%)$ and then pleomorphic xantho-astrocytomas $(16.67 \%)$ and only $8.33 \%$ of lesions (one case) are high grade gliomas which usually don't cause epilepsy if present.

The clinical outcome and degree of controlling the seizures after surgical lesionectomy in drug-resistant epilepsy patients can be evaluated by one of the most popular scales which is Engel classification system. ${ }^{8}$

In this study we used the Engel classification scale to evaluate the outcome post-operatively and during the anti-epileptics withdrawal stages. The evaluation was done by our neurologist colleague.

Regarding to seizure control post-operatively the lesion excision associated with hippocampectomy is known to be better than that without. In other reports, adding corticectomy or hippocampectomy based on intra-operative ECG to the lesion excision has better outcome. However, in other reports proved that the hippocampus just cause amplification or propagation of seizures generated in the lesion, so complete seizure free outcome can be expected with lesion excision alone even if there is ECG findings. ${ }^{7}$

The current study showed that good clinical outcome with only excision of the medial temporal lesions without amygdalo-hippocampectomy and with Engel classification grade I control of the epilepsy to all cases; six cases had already stopped anti-epileptics and only one case continued on small single dose of one anti-epileptic drug while other cases still on withdrawal stage with significant reduction in number and doses of the AEDs .

When the hippocampus appears normal in preoperative imaging, its removal is dangerous as it causes memory affection especially on dominant side so it's better to avoid affecting it when possible. ${ }^{10}$

In all cases in the study there was no memory affection even in one case the parents notice the improvement of studying ability of their daughter.

Although the medial temporal lobe is an area of a complex anatomy, the complications rate is reduced with surgeon who is familiar with that area and with using the navigation systems.

In this study we had only transient complications with no long term sequel in two cases which resolved spontaneously with time; in one case with lesion on left side which approached trans-cortically, the patient suffered from behavior changes for only two months the resolved. And the other case with large lesion on left side also and even extended to the posterior fossa, the patient suffered from mild right hemipariesis grade I for only one month and resolved.

Two cases in our study needed redo due to recurrence of the arachnoid cyst in one case and the other case with huge lesion extending to posterior fossa due to residual part.

In the current study, medial temporal lesions excision procedure without hippocampectomy was proved to be a good management of drug resistant epilepsy. It has an excellent outcome and transient complications without long term sequel.

\section{CONCLUSION}

For medial temporal lobe lesions causing temporal drug-resistant epilepsy, removal of the lesion without removal of amygdala or hippocampus is a very good choice for excellent seizure control with less complication and without affection of the patients' memory. And this is especially if the hippocampus is not infiltrated or affected be the lesion.

\section{REFERENCES}

1. Robert E. Gross and Nicholas M. Boulis. Neurosurgical Operative Atlas; Functional neurosurgery $3^{\text {rd }}$ Ed; Chapter 3 Surgical Anatomy of Temporal Lobe. 2018; 21-52. 
2. Fernández-Miranda JC, De Oliveira E, Rubino PA, et al. Micro vascular anatomy of the medial temporal region: part 1: its application to arteriovenous malformation surgery. Neurosurgery. 2010; $67 \quad$ (3, supplement 1):ons237-ons76.

3. Baris Kucukyuruk, R. Mark Richardson, Hung Tzu Wen, et al. Microsurgical Anatomy of the Temporal Lobe and Its Implications on Temporal Lobe Epilepsy Surgery. Epilepsy Res Treat. 2012; 769-825.

4. F.D. Raslau, I.T. Mark, A.P. Klein, et al. Mark Memory Part2: The Role of the Medial Temporal Lobe; AJNR Am J Neuroradiol; 2015; 36:846-9.

5. Ji Hoon Phi and Chun Kee Chung. Brain tumors in the mesial temporal lobe: long-term oncological outcome. Neurosurg Focus. 2009; 27 (2):E5

6. Soeder BM, Gleissner U, Urbach $\mathrm{H}$, et al Causes, presentation and outcome of lesional adult onset mediotemporal lobe epilepsy. $J$ Neurol Neurosurg Psychiatry, 2009; 80(8): 8949 .
7. Takehiro Uda, Noritsugu Kunihiro, Kosuke Nakajo, et al. Seizure freedom from temporal lobe epilepsy with mesial temporal lobe tumor by tumor removal alone without hippocampectomy despite remaining abnormal discharges on intraoperative electrocorticography: Report of two pediatric cases and reconsideration of the surgical strategy. Surgical Neurology International. 2018; 9:181

DOI: 10.4103/sni.sni_61_18.

8. Engel, J., Van Ness, P.C. and Rasmussen, T.B. With Respect to Epileptic Seizures. In: Engel Jr., J., Ed., Surgical Treatment of the Epilepsies, 2nd Edition, Raven Press Ltd., New York, 1993; 609-21.

9. T. Du, M. Zhu, Z. Dianjiang, W. Lining, Z. Xufei; Beijing/CN. MRI analysis of temporal lobe epileptogenic tumors Poster No.: C-2082 Congress: ECR 2013 Type: European Society of Radiology. DOI: 10.1594/ecr2013/C-2082

10. Helmstaedter C, Petzold I and Bien CG. The cognitive consequence of resecting nonlesional tissues in epilepsy surgery - Results from MRIand histopathology-negative patients with temporal lobe epilepsy. Epilepsia, 2011; $52: 1402-8$ 